\title{
Uma poética do testemunho. "Descrição da guerra em Guernica" de Carlos de Oliveira
}

\author{
Manuel Gusmão \\ Universidad de Lisboa, Portugal \\ manuel.gusmao@gmail.com \\ https://orcid.org/0000-0003-0000-918X
}

Recibido: 1 de agosto de 2019

Aceptado: 20 de setiembre de 2019

Resumo: A guerra é um tema que serve de revelador de características fundamentais da poesia. O que pretendo neste artigo é mostrar como a poesia, através da leitura de um pequeno conjunto de poemas ibéricos sobre a Guerra Civil espanhola, não se limita a construir a referência ao seu tema mas se referencia a si própria.

Palavras-chave: Guerra Civil espanhola; Carlos de Oliveira; guerra; poesia; metapoesia.

\section{A poetics of witness. Carlos de Oliveira's "Descrição da guerra em Guernica"}

Abstract: War is a theme that reveals the fundamental poetry feature. What I want in this article is to show how poetry, by reading a small set of Iberian poems about the Spanish Civil War, is not limited to constructing the reference to its theme but refers to itself.

Keywords: Spanish Civil War; Carlos de Oliveira; war; poetry.

\section{(c) (i) (2)}

La Revista Estudios es editada por la Universidad de Costa Rica y se distribuye bajo una Licencia Creative Commons Atribución-NoComercial-CompartirIgual 3.0 Costa Rica. Para más información envíe un mensaje a 


\section{Dossier: Poesía, armonía y conflictos: ayer y hoy}

"Descrição da guerra em Guernica" é o segundo poema do primeiro conjunto ("Cristal em Sória") de três ciclos poemáticos que formam o penúltimo livro de poemas, Entre duas Memórias (1971), de Carlos de Oliveira. Esta colocação do poema, ao centro do ciclo maior a que pertence, marca localmente uma das significações do título da recolha: "Descrição da Guerra em Guernica" vem entre duas memórias de Espanha: "Nas colinas de António Machado" e "Rio, despedida"; cada uma das quais é já por si uma 'presença' entre outras duas memórias: a memória de um lugar ou sítio geográfico - as colinas em Sória, o lugar onde o Douro nasce, e a leitura da poesia de António Machado, de que se reescreve um poema "Sória", de onde fica no texto português uma palavra castelhana usada pelo poeta espanhol e retomada por Oliveira: "colina_plateada".

Mas para além destes efeitos da colocação do poema, o seu título já nos oferecia uma leitura que aplica o título do volume: "Descrição da Guerra em Guernica" está também, pelo menos, entre duas memórias: a memória de um acontecimento histórico e a memória do quadro de Picasso de 1937. Mas de facto há mais memórias implicadas. Guernica, o nome da povoação basca, bombardeada pela aviação alemã no primeiro ano da Guerra Civil de Espanha, ecoa na sua memória do antifascista, como de vários outros antifascistas portugueses e de inúmeras outras nacionalidades, como sinédoque e metonímia da Guerra Civil e da barbárie nazi-fascista que ela antecipava.

Todas estas multiplicações de sentido vêm da múltipla força referencial atribuível, no título, à palavra Guernica: que é (i) um topónimo do país basco, (ii) o nome de um acontecimento histórico, assim conhecido; é aqui também o nome (iii) de uma famosa pintura de Picasso, e (iv) deste poema de Carlos de Oliveira.

E essa "fama" do quadro constitui um centro dinâmico de significações gerado pelo acontecimento histórico e pelo gesto artístico e político do pintor. O poema, por seu turno, é uma consequência activa, um centro retransmissor e redinamizador e simultaneamente um factor dessa 'fama'. 


\section{Dossier: Poesía, armonía y conflictos: ayer y hoy}

Não nos esqueçamos, o quadro de Picasso é um aglutinador de uma ou várias comunidades imaginárias cujos elementos testemunhavam e chamavam a testemunhar: "somos todos habitantes de Guernica" e podiam mesmo dizer: "contra a besta, somos todos bascos".

O poema "descrição da guerra em Guernica" é a construção de um testemunho, ao mesmo tempo, contemporâneo de um acontecimento duplamente passado e, nesse sentido inactual, porque também contemporâneo nosso e reactualizável a qualquer leitura futura. Este diferimento do testemunho marca-se desde logo na figuração da testemunha.

Trata-se de um poema-ciclo, constituído por dez quase-sonetos, momentos sintacticamente unitários do ciclo. Mas a unidade sintáctica de cada poemeto não impede, antes permite, que entre eles fique precisamente um salto, ou uma dobra do visível. E por isso, a unificação sintáctica dá a ver semanticamente a fragmentação dos tópicos de cada um deles, no poema ciclo, assim como as marcas de fragmentação interna a cada um. É que esses momentos são entretanto alíneas, que comportam sub-alíneas de uma descrição. Se cada fragmento do ciclo, cada quase-soneto termina com um ponto final, à excepção do IV, que termina num ponto de interrogação, no interior de todos eles, a pontuação dominante é a do ponto-e-vírgula, que institui assim o carácter fragmentário do poema e da descrição. Da descrição que dá assim também testemunho do carácter nitidamente fragmentário da pintura.

O poema tece os movimentos de um olhar que não é já o primeiro olhar sobre o quadro. Diz e mostra esses movimentos, as posições em que se detém, as figuras que da pintura toma para seus tópicos.

No seu conjunto, os poemetos começam e acabam por contar movimentos. O primeiro poemeto começa por dizer uma acção dada como representada na pintura e atribuída a uma figura que o poema re(constitui) a partir de um rosto e de

\section{(c) (i) (2)}

La Revista Estudios es editada por la Universidad de Costa Rica y se distribuye bajo una Licencia Creative Commons Atribución-NoComercial-CompartirIgual 3.0 Costa Rica. Para más información envíe un mensaje a 


\section{Dossier: Poesía, armonía y conflictos: ayer y hoy}

um braço. Com esse rosto e esse braço, o poemeto faz um anjo camponês que, com a sua acção, torna visível o que a pintura representa:

Entra pela janela

o anjo camponês;

com a terceira luz na mão;

O verbo de movimento que inicia o poema está conjugado no que chamamos um presente histórico. O poema apresenta-se como uma descrição mas de facto o que ele faz é descrever um processo no tempo. É também por isso que começa por nos referir a terceira luz, o que só pode significar que já contemplou por várias vezes a pintura, e já teve tempo para contar as luzes representadas e escolher a terceira.

Por sua vez o poemeto $X$ é marcado por uma sequência de verbos de movimento: $O$ incêndio desce; sobre os sótãos, os degraus das escadas a oscilar;(...)vibrações percutem os alicerces; e o fogo, veloz agora, fende-os, desmorona toda a arquitectura; as paredes (...) desabam mas o seu desenho sobrevive no ar; sustem-no a terceira mulher; a última, com os braços erguidos; (...). (Oliveira, 2003, p. 309).

Entretanto, os poemetos II a IX caracterizam os tópicos nominais: II - As outras duas luzes (...); III - a linha da garganta, a curva distendida como o gráfico dum grito; o animal fumegante; a mão desta mulher de joelhos entre as pernas do touro; IV - os fragmentos duma estátua ou o construtor da casa já sem fio de prumo; este gládio, esta palavra arcaica; V Mesa, madeira posta; VI - o pássaro; a sua anatomia rápida; VII - Cavalo; reprodutor de luz nos prados; VIII - Outra mulher; IX - Casas desidratadas; as máquinas estranhas.

O anjo camponês é, neste poema, uma figura do testemunho. Internamente ele dá a ver o quadro que representa a destruição de Guernica. Nesse sentido, ele é, ao mesmo tempo, uma testemunha que, pertencendo de alguma maneira à 


\section{Dossier: Poesía, armonía y conflictos: ayer y hoy}

cena representada no quadro, testemunha pelas vítimas. Mas tudo isso é construção do poema que refere o anjo na terceira pessoa. A voz que conta (e começa por contar os três movimentos do anjo), em off, nunca chega a dizer "eu", não é a voz de um sujeito, é a 'voz' do poema que partilha a função testemunhal com o anjo. O poema é uma espécie de testemunha indirecta, que só pode dar testemunho através da descrição do quadro, tornada possível pela invenção da figura do anjo.

Para ler o quadro, deve o anjo ser capaz de minúcia, como testemunha das vítimas deve estar como elas, habituado aos interiores e utensílios dos camponeses; sendo camponês e representando uma visão camponesa do mundo, os seus olhos, rurais, não compreendem bem o que vêem e dão a ver. Nem o poderiam compreender uma vez que a palavra de que dispõem - colheita - de todo não convém ao que têm diante de si.

$O$ anjo que assim surge a abrir o poema, surgirá de novo nos fragmentos VII e IX. Em VII é retomada a dificuldade em compreender o que vê - "o ferro / dos lavradores que o anjo ignora" - Esta será aliás uma das linhas da acusação pelo anjo - o referir o seu inimigo através de palavras que valem no seu universo mas falham gritantemente quando se tenta referir com elas a besta e o seu mundo mecânico - a mesma cal mecânical vibra os seus cutelos - e maquínico Máquinas que voam (II), as máquinas estranhas, os motores com sede (IX), as falsas aves (VI). Em IX, o anjo desolado diz o seu espanto. Das três vezes em que é mencionado no poema será esta a única em que lhe será atribuída a palavra para que possa dizer em discurso directo o que pensa enquanto olha.

\section{(c) (i) (2)}

La Revista Estudios es editada por la Universidad de Costa Rica y se distribuye bajo una Licencia Creative Commons Atribución-NoComercial-CompartirIgual 3.0 Costa Rica. Para más información envíe un mensaje a 


\section{Dossier: Poesía, armonía y conflictos: ayer y hoy}

Casas desidratadas

no alto forno; e olhando-as,

momentos antes de ruírem,

o anjo desolado

pensa: entre detritos

sem nenhum cerne ou água,

como anunciar

outra vez o milagre das salas;

dos quartos; crescendo cisco a

cisco, filho a filho?

As máquinas estranhas,

Os motores com sede, nem sequer

Beberam o espírito das minhas casas;

Evaporaram-no apenas.

Num cenário de destruição, numa fracção de tempo em que se antecipa a iminente derrocada das casas, como se fossem submetidas a uma violenta desidratação pela força destruidora de um alto forno metalúrgico, o anjo, olhando as ruínas, menos que ruínas, ruínas de ruínas, restos, detritos, sente-se como que incapacitado ou excluído da sua função ritual de anunciação do crescimento das casas e do nascimento dos filhos dos seus habitantes. E o espanto desolado atinge de alguma forma o seu clímax, que é também o máximo da incompreensão acusatória: é que "as falsas aves", "as máquinas estranhas" nem sequer absorveram o espírito das suas casas, apenas o evaporaram, o dissolveram no ar.

Todo o poema decorre assim na construção de uma "leitura" interpretativa do quadro de Picasso que (re)constrói nele um combate, um confronto, mortal. (1)

Voltemos à leitura do poema. O anjo que dá a ver o desastre, que ilumina com a luz do candeeiro a cena de maneira a que a ela possamos assistir, como 


\section{Dossier: Poesía, armonía y conflictos: ayer y hoy}

testemunhas implicadas e, ao fim e ao cabo, testemunhas parciais, é um anjo camponês. Ele é, dir-se-á, a testemunha directa e presencial. Mesmo as suas manifestações de ignorância (Prado Coelho, 1979, p. 185, diz e bem "inocência"), de incompreensão, de espantada e desolada perplexidade com aquilo que vê, o configuram como essa testemunha.

$\mathrm{Na}$ construção poética e retórica do confronto, os termos e as figuras da paz e da fragilidade do humano estão do lado dos camponeses, pertencem ao seu mundo e civilização; os termos do outro lado, da guerra, dizem e figuram o metal em brasa, o ferro que marca e endurece os corpos, o calor abrasivo que desidrata e queima, a cal mecânica e os maquinismos estranhos que fabricam o voo e imitam, falsificando-as, as aves; o desespero, o grito preso na garganta, o medo.

$O$ poemeto $V$ é inteiramente preenchido pelo desenvolvimento de um tópico que enuncia no princípio: mesa; cuja proximidade dos homens vem dos gestos morosos do trabalho artesanal e do amor do artesão ao objecto que assim nasce, destinado à casa e com lugar marcado para ser recebido como se fosse, quase,/ uma criança da família.

Já em VI, o tópico do pássaro, tornado mais visível pelo poema, trabalha de forma diferente a contradição dos dois mundos. Por um lado, a sua anatomia é rápida, é uma forma cheia de pressa que se condensa/ apenas o bastante/ para ser visível no céu,/ sem o ferir [...], por outro lado, no quadro da destruição, atónito, abre as asas/ no deserto da mesa;/ e tenta gritar às falsas aves/ que a morte é diferente:\% A morte natural do pássaro seria cruzar o céu com a suavidade/ dum rumor e sumir-se.

Assim, estes dois poemetos exemplificam dois modos do confronto; um, em que a vida camponesa se recorda na luz solar; o outro em que a imposição da destruição e da morte se marca pela divisão de um tópico segundo dois valores: um, o a da solaridade, outro o do incêndio.

\section{(c) (i) (2)}

La Revista Estudios es editada por la Universidad de Costa Rica y se distribuye bajo una Licencia Creative Commons Atribución-NoComercial-CompartirIgual 3.0 Costa Rica. Para más información envíe un mensaje a 


\section{Dossier: Poesía, armonía y conflictos: ayer y hoy}

Em VII é a vez do cavalo ser contrastado entre a respiração na luz e a sua reprodução luminosa e o aqui, no poema que refere o quadro, em que é marcado pelo ferro de uns estranhos lavradores que o anjo desconhece. $O$ ferro endurece de tal forma a plasticidade do cavalo que este se entrega;/ como as bestas bíblicas;/ao tétano e ao furor. Aqui, os mundos que se afrontam distribuem-se pelas duas quadras (o positivo) e os dois tercetos (o negativo) do quase-soneto.

Em VIII, a outra mulher é submetida a uma distribuição dos campos que começa desta vez pelo pesadelo, a opressão e o medo; - e também aqui se retoma o processo de endurecimento que atingira o cavalo e agora transforma os mamilos da mulher em gotas duras/ de leite e medo; quase pedras,/ que a fazem tropeçar, enquanto recorda o amor: espécie de peso que produz/ por dentro da mulher/ os mesmos passos densos.

Em IX, encontramos como já vimos a terceira aparição do anjo e a (sua) tomada de palavra que o poema, porque é doação de linguagem, lhe pode conceder, quando imagina o que ele desolado pensa. É o anjo quem diz na língua do seu pensamento a terrível falta de água a que o fogo destruidor obriga a terra. Entretanto, ele é uma figura que nos permite dar conta da profunda ambivalência que marca os elementos da natureza: se a água, enquanto princípio da vida está em falta, já o fogo que desidrata as casas, queima os tijolos, se torna incêndio é outro no forno do lar medido cisco a cisco, na luz da chama do candeeiro que é condição da visibilidade da cena; enquanto o ar oprime a respiração da (primeira) mulher e se é onde se dissolve o espírito das casas é, também, onde sobrevive o desenho delas.

No último fragmento regressa-se a uma descrição próxima do quadro, indicando-se a localização no seu espaço dos elementos descritos: $O$ incêndio desce; do canto superior direito; as estruturas das casas oscilam; as hélices vibram e percutem os alicerces, e o fogo ganha velocidade, fende-os e desmorona toda a arquitectura. Mas algo acontece nos últimos seis versos - nos versos que

\section{(c) (i) (2)}

La Revista Estudios es editada por la Universidad de Costa Rica y se distribuye bajo una Licencia Creative Commons Atribución-NoComercial-CompartirIgual 3.0 Costa Rica. Para más información envíe un mensaje a 


\section{Dossier: Poesía, armonía y conflictos: ayer y hoy}

equivaleriam aos dois tercetos do poema, se ele fosse um soneto. É que desmoronando-se a construção, desabando as paredes áridas, porque feitas desse material pobre e porque ardidas, desidratadas, o seu desenho (que em arquitectura corresponde ao seu projecto), contudo, sobrevive no ar. Sustém-no/ a terceira mulher; a última; com os braços erguidos;/ a mulher marcada por uma destinação, a mulher em cuja testa se imprime ou grava o suor de uma estrela. Assim, de alguma forma a destruição total e sem remissão possível não se completa. O que não significa que o poema e o quadro não tornem sensível e inteligível uma violência que, desencadeada, não se detém perante nada, destruidora e assassina. Só que essa violência, sendo poderosíssima, não pode tudo. Ela arrasa Guernica, mas não pode apaga-la totalmente, não pode destruir a sua presença na memória dos homens, porque há testemunhas; nem pode apagar o projecto humano de habitar, de residir na terra e nela projectar a sua habitação.

Aqui chegados, temos ainda que nos perguntar de onde, na obra de $\mathrm{CO}$, vem este anjo, de condição camponesa? Vem desde sempre na sua obra. (2)

Mas desde que em Portugal começou a divulgação da obra de Walter Benjamin e antes, para aqueles que o conheciam em alemão ou por tradução francesa ou inglesa, que é irresistível o movimento de aproximação entre o anjo camponês e "o anjo da história" de Benjamin:

Existe um quadro de Klee que se intitula "Angelus Novus". Representa um anjo que parece pretender afastar-se do lugar onde se encontra, imóvel. Os seus olhos estão encarquilhados, a sua

La Revista Estudios es editada por la Universidad de Costa Rica y se distribuye bajo una Licencia Creative Commons Atribución-NoComercial-Compartirlgual 3.0 Costa Rica. Para más información envíe un mensaje a revistaestudios.eeg@ucr.ac.cr. 


\section{Dossier: Poesía, armonía y conflictos: ayer y hoy}

boca, aberta, as suas asas desdobradas. Esse é o aspecto que deve necessariamente ter 0 anjo da história. Tem o rosto virado para 0 passado. Lá, onde se nos apresenta uma cadeia de acontecimentos, ele apenas vê uma só e única catástrofe, que não pára de amontoar ruínas sobre ruínas e de as atirar aos seus pés. Ele bem gostaria de se demorar, de acordar os mortos e reunir os vencidos. Mas do paraíso sopra uma tempestade que se prendeu nas suas asas, e é tão forte que o anjo já não as pode fechar. Essa tempestade empurra-o sem cessar para o futuro ao qual ele vira as costas, enquanto diante dele, até ao céu se acumulam as ruínas. Essa tempestade é aquilo a que chamamos o progresso. (Benjamin, 1983, p. 200)

O que torna o parentesco entre estes dois anjos ainda mais sedutor é o facto de um e outro nascerem de duas obras de dois pintores que, começando no modernismo, do qual vieram a representar tendências divergentes, marcam ambos a primeira metade do século XX. Entretanto, os gestos dos dois escritores constituindo as duas figuras são diferentes: enquanto Benjamin pega num quadro a que Klee chamara "angelus novus" e depois o vai reinventar; no caso de Carlos Oliveira ele começa, como vimos, por inventar a própria figura do anjo a partir de um rosto e de um braço estendido com um candeeiro na mão.

Ambos são sem margens para grandes dúvidas figuras do testemunho. Mas não são o mesmo anjo. O que é que os diferencia, desde logo na própria designação: "anjo da história", "anjo camponês"? O anjo de Benjamin é o anjo de uma disciplina, de um discurso e de uma ciência. Daí também que não possa demorar-se, nem lhe seja permitido o exercício efectivo da compaixão. Por outro lado, este anjo também é um participante da história que se faz (e não apenas daquela que se escreve), acontece apenas que, na lógica da figura, ele está a ser 


\section{Dossier: Poesía, armonía y conflictos: ayer y hoy}

sem cessar empurrado para o futuro, por essa tempestade que é o progresso. Não há equivalente a esta noção de "progresso", na figura construída por Carlos de Oliveira. Na sua obra, aquilo que está mais próximo de representar o tipo de força que o progresso representa em Benjamin é talvez a tempestade das "coisas desencadeadas" (título de um texto de $O$ aprendiz de feiticeiro). Aí se fala de uma "lei fatal, irreversível, do progresso"; "o domínio crescente da natureza pelos homens". Em Carlos de Oliveira, não há contudo a radicalidade da recusa global desse domínio enquanto lei da forma sua contemporânea do progresso. O seu ponto de vista crítico alerta para os graves perigos que essa lei implica "para o próprio homem e [que] poderá transformar-se num boomerang":

Não me refiro já à brutal aventura da destruição que o $20 . .^{\circ}$ aniversário da bomba de Hiroshima, comemorado há pouco, recorda aterradoramente, ou à poluição industrial ameaçando de gangrena a terra, a água, o ar, a flora, a fauna. Refiro-me aos perigos dum outro apocalipse, por dentro, menos espectacular mas também destruidor: a tecnocracia; a habituação passiva ao mecanismo, a uma atmosfera de metal diluído; e a idolatria, a sufocante obsessão dos objectos, fomentada por um aparelho publicitário formidável (Oliveira, 2004, p. 180).

Atento, como se pode observar até no seu vocabulário, ao pensamento crítico do fetichismo da mercadoria e da generalizada alienação que ele provoca, no quadro do que designa como "sociedades neo-capitalistas", a sua resposta persiste em dizer-se como uma terapêutica, uma "medicina humanista", que só pode conceder-se a esperança de vitória se se considerar que "o esquecimento do homem na rápida aridez do mundo [...] não advém do progresso mas do seu uso deturpado" (Oliveira, 2004, p. 181).

As diferenças na concepção do progresso que acentuam a tonalidade trágica do pensamento de Benjamin são indissociáveis da diferença entre o que podem e não podem os dois anjos. Embora, no seu texto, haja outros parágrafos/teses, em que se traçam outros parâmetros da actividade do 


\section{Dossier: Poesía, armonía y conflictos: ayer y hoy}

historiador que, querendo-se guiar pelo materialismo histórico, tem por isso mesmo que o reinventar, a impossibilidade do anjo da história se demorar a acordar os mortos e reunir o vencidos é radical e inultrapassável. E é aqui que lateja a diferença entre os dois anjos. O facto de Carlos de Oliveira a partir de elementos da pintura inventar a figura do anjo camponês e de o fazer intervir em três momentos diferentes da descrição, faz com que o anjo não seja apenas figura de uma testemunha privilegiada, porque é aquele que dá a ver, mas também porque é a figura de um participante. O rosto e o braço estendido com a luz do candeeiro são tão visíveis quanto o cavalo, o touro, etc. Há sempre um plano em que o anjo é composto a partir de uma visibilidade em geral. Dito de outra maneira, ele pode testemunhar também porque participa da catástrofe que dá a ver. Ele não pode evitar a catástrofe, não pode evitar a destruição de Guernica; não pode acordar os mortos. Na sua terceira aparição no poema, a pergunta que faz, diz de outra maneira a desolação que o atinge. Mas o anjo é uma figura do ar e o desenho das paredes que desabam sobrevive no ar. Enquanto testemunha participante, ele vê a terceira mulher, a última, com o suor da estrela tatuado na testa a suster o desenho das casas. E ele, figura do ar, pode então guardá-lo; guardar o projecto de arquitectura daquelas casas. E com esse desenho-projecto ele poderá redimir os vencidos; e poderá anunciar/ outra vez o milagre das salas;/ dos quartos.

A participação assegura que o anjo com a terceira luz na mão e a terceira mulher dividam entre si o processo de negação da negação. Guernica (primeiro momento) foi negada pela destruição (primeira negação), a participação e o testemunho, a participação - testemunho, negam essa negação e produzem o terceiro momento enquanto possibilidade do futuro, pela constituição de uma memória insubmissa.

E podemos citar agora da terceira tese de Benjamin:

\section{(c) (i) (2)}

La Revista Estudios es editada por la Universidad de Costa Rica y se distribuye bajo una Licencia Creative Commons Atribución-NoComercial-CompartirIgual 3.0 Costa Rica. Para más información envíe un mensaje a 
Dossier: Poesía, armonía y conflictos: ayer y hoy

de tudo o que alguma vez aconteceu nada deve ser considerado como perdido para a história. É certo que é apenas à humanidade libertada que pertence plenamente o seu passado. Quer isto dizer que para ela apenas, em cada um dos seus momentos, o seu passado se tornou citável. Cada um dos instantes que ela viveu torna-se uma citação na ordem do dia - e esse dia é justamente o último (Benjamin, 1983, p. 196).

\section{Referências bibliográficas}

Barrento, J. (ed.) (2010). O Anjo da História. Obras escolhidas de Walter Benjamin. Lisboa: Assírio \& Alvim.

Benjamin, W. (1983). Thèses sur la philosophie de l'histoire. Essais 2: 19351940) (pp. 195-207). Paris: Denoël/Gonthier.

Oliveira, C. de (2003). Descrição da guerra em Guernica. Entre duas memórias. Trabalho poético (pp. 300-309). Lisboa: Assírio \& Alvim.

Oliveira, C. de (2004). "Coisas desencadeadas". O Aprendiz de feiticeiro (pp. 179-181). Lisboa: Assírio e Alvim.

Prado Coelho, E. (1979). Em torno de um poema de Carlos de Oliveira. A Letra litoral (pp. 180-186). Lisboa: Moraes editores.

\section{Notas:}

Nota 1: Quem são aqueles que se confrontam? São várias as respostas possíveis, para além da resposta imediata que resulta da força referencial de que o nome 


\section{Dossier: Poesía, armonía y conflictos: ayer y hoy}

próprio do título está investido. Trata-se de um confronto - entre as imagens da paz e da guerra; entre a fragilidade do humano e "as bestas bíblicas"; entre as imagens de uma civilização de base camponesa e as de uma indústria moderna de guerra. Destas três respostas, é a última que é a mais problemática, até porque se arrisca a consentir uma argumentação segundo a qual Guernica representaria apenas um momento do triunfo histórico fatal da produção industrial sobre uma sociedade camponesa tradicional.

Nota 2: Vem desde as paisagens da infância, na Amazónia e na Gândara, do livro Turismo, reescrito. Vem desde "Xácara das bruxas dançando" e de tudo o que permite relacionar a sua poesia, na primeira fase da sua obra, com o romanceiro da tradição oral e a civilização camponesa; mas vem também e significativamente da segunda fase da sua obra. Curiosamente, é mesmo nesta segunda fase, em que alguns vêem um abandono por Carlos de Oliveira das suas preocupações sociais, que os camponeses surgem mais nitidamente como um tópico poderoso e insistente.

O tópico surge nesse magnífico livro que marca as poderosas transformações da segunda fase, Sobre o lado esquerdo e, mais precisamente da sequência II do poema "Desenho infantil". Já aliás aqui se pressente que Finisterra está a chegar. Os camponeses, esses, destinados às sepulturas rasas, aos estratos de mortos sobre mortos, servem-se do pinho, dos adobes (materiais perecíveis), erguem casas na lama, manuseiam utensílios tão rudimentares como a charrua de madeira. Passam sobre a areia e as pegadas somem-se depressa, "mas carregam aos ombros a pedra do meu lar (pensa a criança obscuramente) e a minha lápide futura". (OLIVEIRA: 2003: 190)

Estes camponeses são transumantes e o rápido apagamento das suas pegadas na areia mostra como estão destinados a desaparecer enquanto grupo social. Entretanto, marca-os essa intimidade com a morte, com os materiais perecíveis e 


\section{Dossier: Poesía, armonía y conflictos: ayer y hoy}

os instrumentos rudimentares. Mas ao mesmo tempo a sua caminhada é mais longa que a vida de um qualquer como é aquele que os escreve.

Em Pastoral, finalmente, são referidos no título de um poema, "Camponeses", que de novo é dedicado ao seu desaparecimento, absorvidos pelo crepúsculo.

No texto "Micropaisagem" (1969), de O Aprendiz de Feiticeiro, encontramos a justificação autobiográfica da mitologia pessoal e política que se constrói em torno dos camponeses: «... Cresci cercado pela grande pobreza dos camponeses, por uma mortalidade infantil enorme, uma emigração espantosa. Natural que tudo isso me tenha tocado (melhor, tatuado). O lado social e o outro, porque há outro também, as minhas narrativas ou poemas publicados (...) nasceu desse ambiente quase lunar habitado por homens e visto, aqui para nós, com pouca distanciação» (204). Se tomarmos esse outro lado como o do trabalho formal o que a frase sobretudo afirma é que essa tatuagem se manifesta também nesse obsessivo trabalho da forma.

La Revista Estudios es editada por la Universidad de Costa Rica y se distribuye bajo una Licencia Creative Commons Atribución-NoComercial-Compartirlgual 3.0 Costa Rica. Para más información envíe un mensaje a 